\title{
KINETICS OF COMPLEX FORMATION OF METALS WITH ORGANIC LIGANDS IN ANALYTICAL CHEMISTRY
}

\author{
I. P. Alimarin
}

V. I. Vernadsky Institute of Geochemistry and Analytical Chemistry, USSR Academy of Sciences, and M. V. Lomonosov Moscow State

University, USSR

\begin{abstract}
The present state of studies of the kinetics of complex formation of metals with organic ligands in analytical chemistry is summarized. Fast and slow reactions of complex formation of labile and inert complexes are discussed. The application of ligand replacement and exchange reactions of central atoms in the inner sphere of complex compounds in spectrophotometric analysis, solvent extraction and sub-stoichiometric separation of elements is described. The prospects of using kinetic regularities of complex formation in chemical analysis are outlined.
\end{abstract}

\section{INTRODUCTION}

Analytical chemistry of complex compounds of metals with organic ligands has developed through three stages. At first intense investigations of new organic reagents for metal ions were carried out. Then researches were directed to the elucidation of the effect of the structure of reagents on their reactivity, taking into account the presence of functional-analytical groups and substituents: simultaneously work on the mechanisms of complex formation in solution and the calculation of different constants was carried out. At last, during the past few years the studies on the structure of complex compounds using quantum-chemical methods have been developed.

So far the problems of rates of formation, dissociation of metal chelates, and replacement of their ligands or central atoms were mainly considered in special papers or books on coordination chemistry ${ }^{1-5}$.

The kinetic problems of complex formation began to be studied in analytical chemistry only in recent years. Much more attention in theoretical and practical works has been paid to kinetic methods of analysis based on the use of catalysed reactions of oxidation and reduction; Yatsimirsky has a high reputation in the field for the development of the theoretical fundamentals of this highly selective method ${ }^{6}$. The book by Mark and Rechnitz published recently ${ }^{7}$ also mainly deals with the applications of catalysed reactions.

It is worthwhile to note that works on analytical chemistry mainly describe the correlations between time of a reaction and its run. that is 
reaction order, rate constant, and activation energy are not given. It is impossible to draw any conclusions about the reaction mechanism when these parameters are absent.

It is well known that reactions can be divided into slow and fast ones. Reactions whose half-times are larger than about $10 \mathrm{~s}$ are considered slow; for such reactions conventional instrumental methods can be used to follow and measure the process of the interaction of ions with the reagent. Fast reactions whose half-times are less than $10 \mathrm{~s}$ are studied by very rapid methods of mixing the solutions and special measurement technique ${ }^{7-9}$. Both fast and slow reactions are of interest for analytical chemistry.

\section{FAST REACTIONS OF COMPLEX FORMATION}

Most reactions of metal ions with organic ligands, giving labile complexes, are processes with complex formation times of less than $0.1 \mathrm{~s}$. The study of the kinetics of such reactions is of interest for analytical chemistry, initially from the point of view of the elucidation of the mechanism of complex formation, for example, that of ligand attack and ligand transfer from the inner sphere of the complex, or that of the formation of unstable intermediates (for instance, in spectrophotometric studies by filming absorption spectra). Such investigations make it possible to penetrate 'the black boxes', that is to obtain information about the intermediates as well as the initial and final species. This very important branch of analytical chemistry is only in its first stages and it should be developed quickly. Different methods are used to study such reactions (Figure 1), for example, the flow method, relaxation spectrophotometry, the impulse method and other methods ${ }^{8.9}$.

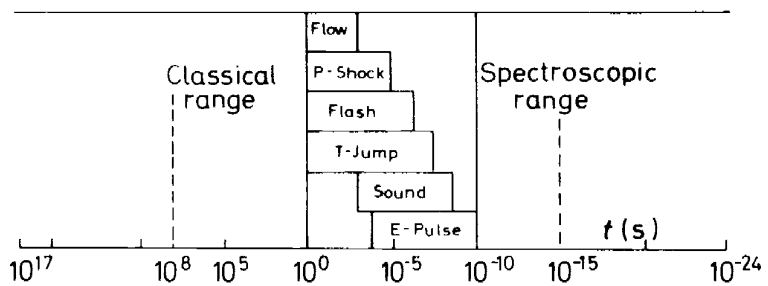

Figure 1. Methods for very rapid reactions in solution and their time ranges ${ }^{8}$

In recent years the method of nuclear magnetic resonance has been used to study the rate of interaction of the metal ion with the ligand or the rate of exchange reactions ${ }^{9,10}$. Probably, picosecond spectroscopy using a pulsed laser $^{11}$ will prove to be useful.

\section{SLOW REACTIONS OF COMPLEX FORMATION}

A consideration of the literature of the kinetics of the reactions of complex formation of metals with organic ligands shows that most investigations meet the demands of coordination chemistry without any indication of the 
applicability of slow reactions in chemical analysis. Studies on the rates of formation of coloured compounds and on solvent extraction kinetics have begun to appear only in the last five years.

So far there are few well-studied kinetic reactions of complex formation with organic ligands. There are few data on the role of the ligand itself. A consideration of the available information shows that ligands with strong fields, for instance, chelate-forming amines, aminopolycarboxylic acids, EDTA and related compounds, are suitable for analytical purposes. Such polydentate ligands tend to give slow formation of metal chelates.

The nature of the bond is of importance. If the bond is considerably covalent, its formation and rupture are slow processes; compounds with such bonds are most suitable for chemical analysis.

Some research works have been devoted to the study of the kinetics of complex formation with $\beta$-diketones, for example, with benzoylacetone, acetylacetone and thenoyltrifluoroacetone. Rate constants, activation energy and entropy of activation have been found. Some aspects of kinetics of tautomerization, protonization of reagents and effect of different substituents in the reagent molecule have been considered. It was shown, for example, that replacement of the $\mathrm{CH}_{3}$ group by a $\mathrm{C}_{6} \mathrm{H}_{5}$ group retards the reaction ${ }^{12-14}$.

An interesting phenomenon was noticed for the reactions of $\mathrm{Mo}^{\mathrm{v}}$ with oximes of the aromatic series. During the reaction with $\alpha$-benzoyloxime a pink colour appears; it disappears in 5-10 min but after 24 hours the solution becomes deep-violet. In this case the consecutive formation of two chelate compounds takes place.

Slow reactions with some organic reagents, for instance, with xylenol orange and alumocresol, at $\mathrm{pH} 2.5-5.0$, are typical for aluminium ions ${ }^{16}$.

Works on the kinetics of complex formation mostly deal with studies of the mechanisms or conditions of solvent extraction of metal chelates ${ }^{17-20}$.

The constitution of the electronic shells of the central metal atom and the stereochemistry of the complex are other important factors in the kinetics of complex formation. Octahedral $d^{3}$-complexes and low-spin $d^{4}, d^{5}$ and $d^{6}$ systems are inert with respect to reactions of the ions in aqueous solutions. Such complexes with the coordination number of six can be formed by $\mathrm{Cr}^{\mathrm{III}}, \mathrm{Co}^{\mathrm{III}}, \mathrm{Fe}^{\mathrm{III}}, \mathrm{Mo}^{\mathrm{III}}, \mathrm{Au}^{\mathrm{III}}$ and some platinum metals. Those with the coordination number of four are formed by, for example, $\mathrm{Pt}^{\mathrm{II}}$ and $\mathrm{Pd}^{\mathrm{II}} 2,17$.

The kinetic inertness of the chromium aquo-ion, $\left[\mathrm{Cr}\left(\mathrm{H}_{2} \mathrm{O}\right)_{6}\right]^{3+}$, at room temperature, is very well known. This property is used for the separation of chromium from other elements forming labile complexes, for example, in the extraction of corresponding chelates. The rate of reaction of this ion can be increased by heating; it is carried out, for instance, in the photometric determination of chromium as a complex with EDTA.

$\mathrm{Co}^{\mathrm{II}}$ at $25^{\circ} \mathrm{C}$ and $\mathrm{Cr}^{\mathrm{III}}$ at $80^{\circ} \mathrm{C}$ form coloured compounds with PAR [4-(2pyridylazo)-resorcinol]. This difference was used for the photometric determination of cobalt in the presence of chromium ${ }^{21}$. The formed complex compounds of cobalt and chromium are stable in solution in $2 \mathrm{~N} \mathrm{H}_{2} \mathrm{SO}_{4}$ during 24 hours, while the compounds of many other metals decompose very rapidly with PAR $^{21}$; this difference permits the determination of cobalt and chromium in the presence of 1000 -fold amounts of other elements.

We used the inertness of chromium ions for the complexometric 
titration of $\mathrm{Ni}^{2+}, \mathrm{Cu}^{2+}$ and $\mathrm{Fe}^{3+}$ in the presence of large amounts of chromium by the amperometric method. The method of separation of some elements from kinetically inert ions of $\mathrm{Cr}^{\mathrm{III}}, \mathrm{Co}^{\mathrm{III}}$ and $\mathrm{Au}^{\mathrm{III}}$ on chelate-forming ion exchangers has been described ${ }^{22}$.

The idea of accelerating the reactions of inert ions by ligand catalysis is of great interest ${ }^{17,18}$. The study of chromium(III) extraction by thenoyltrifluoroacetone and 8-hydroxyquinoline showed that the complexes were not formed and not extracted at room temperature. The chromium complex is extracted more rapidly if ammonium fluoride is added to the aqueous phase (Figure 2). Ligand catalysis with the bicarbonate ion was used for the

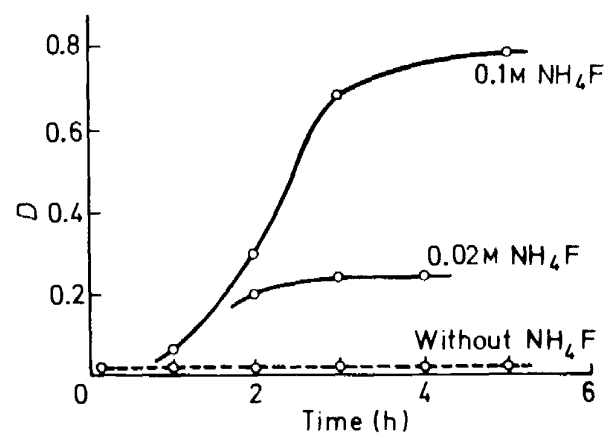

Figure 2. Optical density of the extract of chromium(III) thenoyltrifluoracetonate in the presence and in the absence of $\mathrm{NH}_{4} \mathrm{~F}$ at $\mathrm{pH} 5.4-5.7$

indirect determination of this ion by its catalytic action on the reaction of chromium with EDTA ${ }^{23,24}$. The formation of chromium hydroxyquinolinate can be accelerated with acetate, fluoride and other ions ${ }^{2 \div 26}$.

Yatsimirsky ${ }^{6}$ points out that a number of the reactions of replacement in the inner sphere of the complex are homogeneously catalysed and can be used in quantitative analysis.

The rate of complex formation also depends on some other parameters, for example, ionic state of the element (polynuclear or hydroxo-ions), reagent concentration, $\mathrm{pH}$ of the solution ${ }^{17}$, temperature and nature of the solvent ${ }^{27,28}$. The last factor is of importance when the reaction proceeds in a non-aqueous solvent, for instance, after the extraction. In one of our investigations we firstly extracted germanium with $N$-benzoyl- $N$-phenylhydroxylamine into benzene for the separation from other elements and then added an ethanolic solution of phenylfluorone to the extract. This lead to the formation of a deep-coloured tertiary complex; the rate of formation in the organic phase was slow, equilibrium being attained after $30 \mathrm{~min}^{29}$.

It has been shown that steric effects are of great importance in the kinetics of complex formation ${ }^{30,31}$. 


\section{REPLACEMENT OF LIGANDS IN COMPLEX COMPOUNDS}

Theoretical problems of the rates and the mechanisms of ligand replacement in complex compounds have mainly been considered for exchange processes of inorganic ligands or amines. These have been examined in detail in the book by Langford and Gray ${ }^{1}$. In analytical chemistry, research work dealing with ligand replacement processes and corresponding rate studies was begun quite recently. We have already mentioned some work on the kinetics of the replacement of water molecules in inert aquo-ions with other ligands.

It is worthwhile to note the success of the work of Japanese chemists on the kinetics and mechanism of complex formation. Tanaka and co-workers ${ }^{32-35}$ studied the systems: copper, mercury, nickel and other metal ions-aminopolycarboxylic acids-4-(2-pyridylazo)-resorcinol. Generally, any complexometric titration with metallochromic indicators has to be considered as ligand replacement.

The 'stop-method' was used to study the kinetics of the reactions of alkaline earth and some transition elements with metallochromic indicators and their replacement in complexes with complexone. Some methods of determining metals using the change of ligand exchange rates have been developed $^{36}$. A reaction of ligand replacement has been used for the photometric determination of erbium ${ }^{37}$.

The study of the kinetics and the mechanism of ligand replacement for EDTA molecules in chromium chelates ${ }^{38,39}$ is of interest. A new kinetic method of determining rare earth elements in the presence of other rare earths is a wonderful example of the use of the rate of ligand replacement in analytical chemistry; the method developed by Budarin, Yatsimirsky and Khachatryan ${ }^{40}$ is based on the difference between the rates of two replacement reactions of polydentate ligands. The reaction of EDTA with the coloured complexes of the rare earth elements, with xylenol orange indicator, was used for this purpose:

$$
\mathrm{LnX}+\mathrm{EDTA} \rightleftarrows \mathrm{LnEDTA}+\mathrm{X}
$$

where

$$
\mathrm{Ln}=\mathrm{a} \text { rare earth element ion }
$$$$
X=\text { an anion of xylenol orange }
$$

$$
\mathrm{EDTA}=\text { an EDTA ion }
$$

It is a first-order reaction, and the magnitude of the effective constant of the reaction rate varies from $236 \mathrm{~s}^{-1}$ for $\mathrm{Ce}^{\mathrm{II}}$ to $30 \mathrm{~s}^{-1}$ for $\mathrm{Lu}$ in the rare earth element series. The products of the reaction do not absorb at $540 \mathrm{~nm}^{40-42}$.

Using the differences between the rates of the replacement of inner sphere ligands a precise and rapid method for the spectrophotometric determination of yttrium in a mixture with samarium has been developed ${ }^{40}$. This example shows that closely related elements, giving electronic absorbance spectra that are identical with those of the reagent, can be determined in the presence of each other by the method of kinetic spectroscopy, if the differences between the rates of ligand replacement are exploited.

Eigen and Kustin ${ }^{8}$ point to the presence of a certain dependence of the 


\section{P. ALIMARIN}

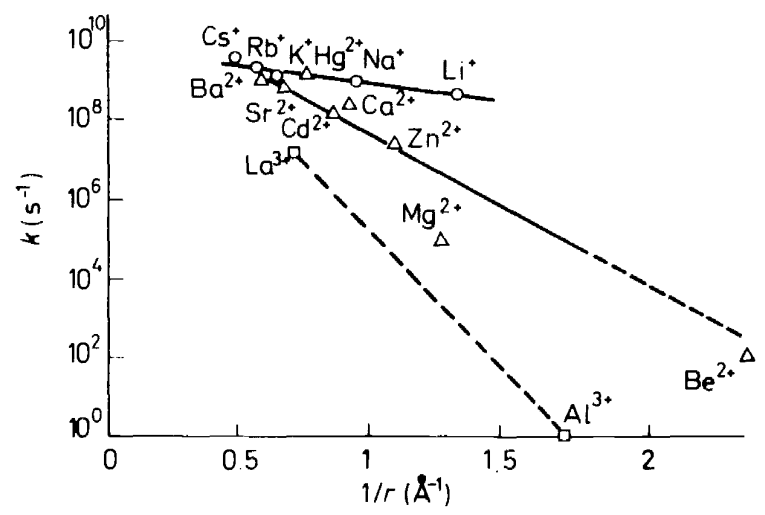

Figure 3. The first-order rate constant for formation of complexes of some metals: dependence on ionic size ${ }^{8}$

rate of a complex formation reaction on ionic size (Figure 3). Such a dependence has been established by Geiger for the reaction of murexide with rare earth elements ${ }^{43}$ (Figure 4).

Poluektov and co-workers ${ }^{44}$ used the method of competitive ligands for determining closely related rare earths by the colour reaction with quinalizarin, using benzoic acid as a competitive ligand-substituent. In this case

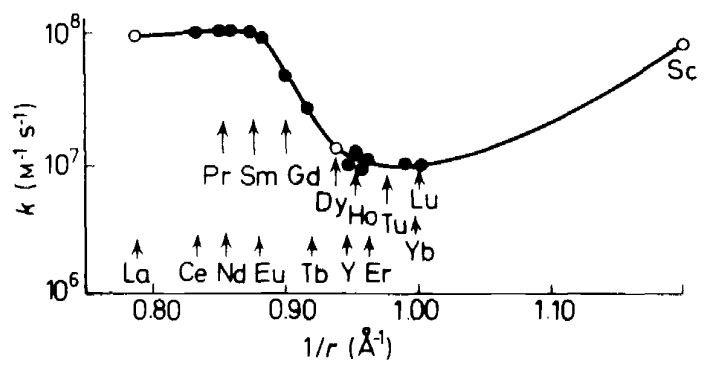

Figure 4 . The rate constant of complex formation as a function of metal ion radius ${ }^{43}$

a related regularity is also observed though the kinetics of the replacement is not described (Figure 5).

In reactions of ligand replacement as well as simple replacement introduction to the inner sphere of the complex of ligands of different nature can take place. This causes a change in coordination number of the element and the formation of an intermediate or a final complex with two types of ligand in the inner sphere. Such a case was described in work ${ }^{45}$ on the kinetics of the replacement of xylenol orange by EDTA in zirconium and hafnium complexes. 


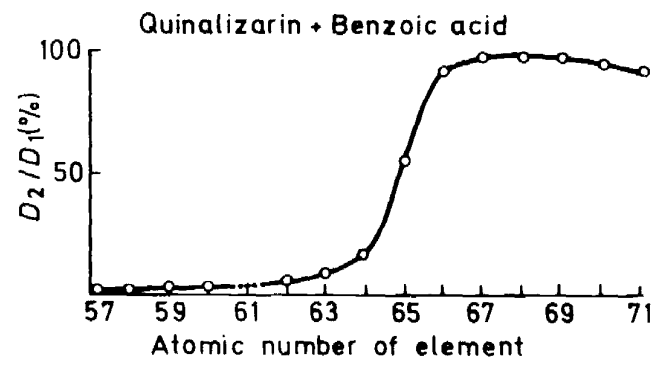

Figure 5. Different ability of rare earth elements to replace ligands in complex compounds ${ }^{44}$

The formation of mixed complexes makes the calculation of rate constants of reactions difficult. The rate of ligand replacement can also depend on whether the replacement is from an octahedral or tetrahedral configuration. This was demonstrated in the study of the kinetics of the extraction of $\mathrm{Zn}$. $\mathrm{Ni}, \mathrm{Co}$ and $\mathrm{Cd}$ complex compounds with diphenylcarbazone and its ana$\operatorname{logues}^{46}$. The steric effect ${ }^{47}$ and the trans effect ${ }^{48}$ are of essential importance in the kinetics of ligand replacement.

The method of ligand replacement is widely used in masking reactions for increasing their selectivity ${ }^{49}$. The rate of replacement should also be taken into account in such cases. For example, when adding EDTA to a tartrate solution of zirconium and titanium, the tartrate ligand in the zirconium complex is fully replaced by EDTA while it is not replaced in the tartratetitanium complex. Hence, the complexometric titration of zirconium in the presence of titanium is possible. However, it has been established that the rate of replacement of the tartrate ion depends on the $\mathrm{pH}$ of the solution ${ }^{50}$ (Figure 6).

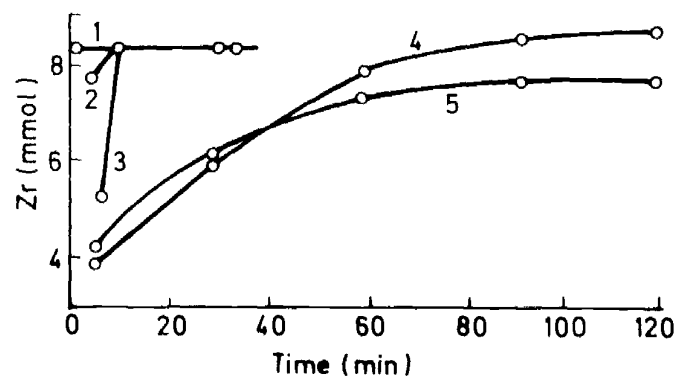

Figure 6. The rate of replacement of tartrate ligands by EDTA in the tartrate complex of zirconium. Curves $1-5$ correspond to $\mathrm{pH}$ values of $1-5$

It is often necessary to select optimum variants during the analysis of complex equilibria and the study of the mechanisms of complex formation or ligand replacement. The graph method ${ }^{51,52}$ is very useful in such cases. 


\section{REPLACEMENT OF METALS IN COMPLEX COMPOUNDS}

The reactions of replacement of the central metal atom in the inner sphere of the complex by another competitive metal are widely used in analytical chemistry for determination, separation and concentration of metal traces $^{53,54}$.

Exchange reactions have been mainly studied by the solvent extraction method, according to the scheme:

$$
n\left[M^{1}\right]^{m+}(a q)+m M^{11} A_{n} \text { (org) } \Leftrightarrow n M^{1} A_{m} \text { (org) }+m\left[M^{11}\right]^{n+}(a q)
$$

The exchange series have been established for a number of metal chelates, for example for cupferronates ${ }^{53,54}, \mathrm{Fe}^{\mathrm{III}}>\mathrm{Ga}>\mathrm{Cu}^{\mathrm{II}}>\mathrm{Sc}>\mathrm{In}>\mathrm{Hg}^{\mathrm{II}}>\mathrm{Al}$, and for diethyldithiocarbaminates, $\mathrm{Hg}^{\mathrm{II}}>\mathrm{Ag}>\mathrm{Pd}^{\mathrm{II}}>\mathrm{Cu}^{\mathrm{II}}>\mathrm{Tl}^{\mathrm{III}}>\mathrm{Ni}>$ $\mathrm{Pb}>\mathrm{Co}>\mathrm{Cd}>\mathrm{Fe}^{\mathrm{III}}>\mathrm{Mn}^{\mathrm{II}}$.

The study of such series enabled some methods of separation of elements to be elaborated. For example, gallium can be separated from indium using the extraction with copper cupferronate. The method of extraction and spectrophotometric determination of copper by the exchange reaction with lead diethyldithiocarbaminate is widespread ${ }^{57}$. We used the method of replacement chromatography of metal diethyldithiocarbaminates in neutronactivation analysis for determining metal traces in pure yttrium and molybdenum $^{58}$. The exchange reactions of 8 -mercaptoquinolinates, dibutyldithiophosphates, carboxylates ${ }^{57}$ and complexes with EDTA ${ }^{59,60}$ have been studied.

The metal atom is replaced rapidly in a number of the above reactions. However, in some cases of practical importance the rate of the exchange process is slow. Thus the factors affecting the rates of exchange reactions should be taken into account. It has been shown ${ }^{61}$ that the rate of extraction

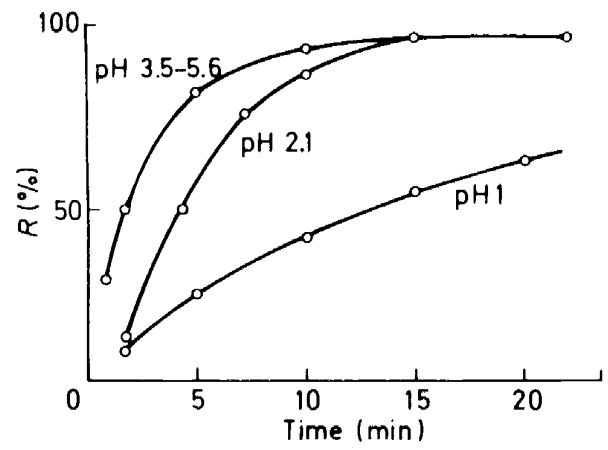

Figure 7. The effect of time and $\mathrm{pH}$ on the extraction $(R)$ of copper $\left(1 \times 10^{-6} \mathrm{M}\right)$ with zinc dithizonate $\left(1 \times 10^{-5} \mathrm{M}\right)$ in $\mathrm{CCl}_{4}{ }^{61}$

in the exchange system depends on the concentration of the reagent-complex and its kinetic lability, but should be independent of $\mathrm{pH}$ above a certain $\mathrm{pH}$ value. An example of such a regularity is given in Figure 7; the rate of extraction of copper by zinc dithizonate in $\mathrm{CCl}_{4}$ increases with increasing $\mathrm{pH}$ and 
then ceases to depend on the $\mathrm{pH}$ value above a certain limit value ${ }^{61}$. It has also been shown that an increase of the aqueous phase concentration of the ions replaced, leads to a decrease in the rate of extraction. The rate of exchange is in certain cases proportional to the distance between the positions of the exchanging metals in the replacement series ${ }^{62}$.

The use of small concentrations of a reagent-complex of high extraction constant allows the rate of extraction to be retarded. Thus, in the abovementioned series for metal diethyldithiocarbaminates each metal replaces any following metal from its complex dissolved in $\mathrm{CCl}_{4}$. However, there are pairs of elements for which full replacement does not take place after shaking for $5 \mathrm{~min}$. For the pairs, $\mathrm{Hg}-\mathrm{Pd}, \mathrm{Ag}-\mathrm{Pd}, \mathrm{Cu}-\mathrm{Ni}$ and $\mathrm{Ni}-\mathrm{Tl}^{\mathrm{III}}$ even a partial replacement is not observed after shaking for 15-60 min. We have already mentioned such kinetically inert complexes.

Cobalt and palladium are not replaced from their complexes by any of the metals even after long shaking. This is connected with the kinetic inertness of the corresponding chelates ${ }^{55}$, which protects the separation of metals but can also be used for the separation of labile complexes from inert ones. For example, cobalt is not replaced from its diethyldithiocarbaminate by any single metal while all other elements are replaced by mercury forming the very stable complex with DEDTC. This permits the spectrophotometric determination of cobalt traces in the presence of many other elements ${ }^{63}$.

The above method was used, by Japanese chemists, for determining cobalt in water which was applied to cool an atomic reactor ${ }^{64}$.

Some other works of practical interest, in which peculiarities of exchange reactions of metals in chelates are described, have been published. For instance, the work devoted to the replacement of praseodymium by iron(III) in the complex with xylenol orange ${ }^{65}$.

The special features of the kinetics of the exchange of metal ions in complexes with trans-1,2-diaminocyclohexane $N, N, N^{\prime}, N^{\prime}$-tetraacetate were used by Margerum ${ }^{66,67}$ for quantitative determination of alkaline earth and rare earth metals in their mixture, using photo-oscilloscopy and the stop-method.

\section{CONCLUSION}

In this report I have not tried to generalize all known theoretical and experimental data on the kinetics of complex formation in analytical chemistry. I have attempted to encourage more interest in this promising field, which gives insight into the mechanisms of complex formation reactions and will soon yield some new selective kinetic methods of determination and separation of elements.

\section{REFERENCES}

1 K. H. Langford and H. B. Gray, Ligand Substitution Process, W. A. Benjamin, New York, Amsterdam (1965).

${ }^{2}$ F. Basolo and R. G. Pearson, Mechanism of Inorganic Reactions. A Study of Metal Complexes in Solution, John Wiley and Sons, New York (1967).

3 J. Lewis and R. G. Wilkins, Modern Coordination Chemistry. Principles and Methods, Interscience, New York (1960).

${ }^{4}$ M. T. Beck, Chemistry of Complex Equilibria, Van Nostrand Reinhold. London (1970). 


\section{P. ALIMARIN}

${ }^{5}$ F. P. Dwyer and D. P. Mellor, Chelating Agents and Metal Chelates, Academic Press, New York (1964).

${ }^{6}$ K. B. Yatsimirsky, Kinetic Methods of Analysis, Pergamon Press, Oxford (1966).

7 H. B. Mark and G. A. Rechnitz, Kinetics in Analytical Chemistry, Interscience, New York (1968).

8 M. Eigen and K. Kustin, ICSU, Reriew of World Science, 5. 97 (1963).

${ }^{9}$ E. F. Caldin, Fast Reaction in Solution, Blackwell, Oxford (1964).

10 J. D. Carr, K. Torrance. C. J. Cruz and C. N. Reilley. Anal. Chem., 39, 1359 (1967).

11 P. M. Renitzepis and C. I. Mitschele, 4nal. Chem., 42. N14. 1-A (1970).

12 A. V. Celiano, M. Cefola and P. S. Centile, J. Phys. Chem., 66, 1132 (1962); 65, 2194 (1961).

13 W. K. Ong and R. H. Prince, Nature, 208, 1201 (1965).

14 R. W. Taft and E. H. Cook, J. Am. Chem. Soc., 81, 46 (1959).

15 V. M. Peshkova and E. S. Guryeva, Vestn. Mosk. Gos. Univ., Ser. II, Khim. 1, 79 (1970).

16 A. I. Cherkasov, B. I. Kazakov and V. S. Tonkoshkurov. Zh. Anal. Khim., (Mosk.) 22, 1464 (1967).

17 Yu. A. Zolotov, Extraction of Chelate Compounds, Humphrey, London (1970).

18 I. P. Alimarin. Yu. A. Zolotov and V. A. Bodnya. Pure and Appl. Chem.. 25, 667 (1971).

${ }_{19}$ G. N. Ozerova. N. V. Melchakova and V. M. Peshkova, Visn. Mosk. Gos. Lnit.., Ser. II, Khim., $5,102(1968)$.

20 N. P. Rudenko and V. I. Kuznetsov, Vestn. Mosk. Gos. Univ., Ser. II, Khim. 5, 91 (1968).

${ }^{21}$ S. A. Akhmedov. O. A. Tataev and P. P. Abdulaev. Zavodsk. Lab. 37. 756 (1971).

22 H. R. Hering, Chelathildende Ionenaustauschen. Acad.-Verlag, Berlin (1967).

${ }^{23}$ S. R. Agger and C. E. Hedrick, J. Chem. Educ., 43, 541 (1966).

${ }^{24}$ V. K. Rao, D. S. Sundar and M. N. Sastry, Chemist-Analyst, 54, 86 (1965).

25 V. A. Bodnya. I. P. Alimarin and T. F. Sedletskaya, Izvest. Akad. Nauk SSSR, Ser. Khim., 6, $1192(1968)$.

26 Yu. A. Zolotov, O. M. Petrukhin, L. A. Jzosenkova and E. V. Krasilnikova, Zh. Neorgan. Khim., 17, 2563 (1971).

27 E. S. Amis, Solvent Effects on Reaction Rates and Mechanisms, Academic Press, New York (1966).

${ }^{28}$ I. P. Candin, K. A. Taylor and D. T. Thompson, Reactions of Transition Metal Complexes, Elsevier, Amsterdam (1968).

29 I. P. Alimarin. E. V. Smolina, I. V. Sokolova and T. F. Firsova, Zh. Anal. Khim., (Mosk.), 25, $2287(1970)$.

30 D. B. Rorabacher, T. S. Turan, J. A. Defever and W. G. Nickels, Inorg. Chem., 8, 1498 (1969).

31 M. J. Carter and J. K. Beattie, Inorg. Chem., 9, 1233 (1970).

32 S. Funahashi and M. Tanaka, Bull. Chem. Soc. Japan, 43, 763 (1970).

33 S. Funahashi, S. Yamada and M. Tanaka, Bull. Chem. Soc. Japan, 43, 769 (1970).

${ }^{34}$ S. Funahashi, M. Tabata and M. Tanaka, Bull. Chem. Soc. Japan, 44, 1586 (1971).

35 M. Tanaka, S. Funahashi and K. Shirai, Inorg. Chem., 7, 573 (1968); 8, 2159 (1969); 9, 2092 (1970); 10, 257 (1971).

36 J. C. Hanna and S. Sigia, Anal. Chem., 36, 2023 (1964).

37 J. Inczédy, Talanta, 17, $1212(1970)$.

${ }^{38}$ D. Banerjea and F. Chaudhuri, J. Inorg. Nucl. Chem., 32, 2697 (1970); 30, 3259 (1968).

39 D. Banerjea and F. Chaudhuri, Z. Anorg. Allgem. Chem., 372, 268 (1970).

${ }^{40}$ L. I. Budarin, K. B. Yatsimirsky and A. G. Khachatryan, Zh. Anal. Khim., (Mosk.). 24, 1499 (1971).

41 K. B. Yatsimirsky and L. I. Budarin. Dokl. Akad. Nauk SSSR. 170. 1107 (1966).

12 I. P. Thuchenko, I. I. Budarin and K. B. Yatsimirsky. Teor. i Eksperim. Khim. 5. 507 (1969); $4,469(1968)$.

43 G. Geiger, Ber. Bunsenges. Physik. Chem., 69, 617 (1965).

44 N. S. Poluektov, A. I. Kirillov and R. S. Lauer, Zh. Anal. Khim., (Mosk.), 27, 460 (1972).

45 L. I. Budarin, R. V. Suchkova and K. B. Yatsimirsky, Zh. Neorgan. Khim., 16, 1862 (1971).

46 B. E. McClellan and H. Freiser, Anal. Chem., 36, 2262 (1964).

47 D. B. Rorbacher and D. B. Moss, Inorg. Chem., 9, 1314 (1970).

48 A. A. Grinberg. Vvedenie r Khimiyn Kempleksnvkh Soedinenii. Izd. 'Khimiya'. Moscow (1966).

49 D. D. Perrin, Masking and Demaskiny of Chemical Reaction, Wiley-Interscience, New York (1970).

so T. P. Kirevina, A. P. Stepanova and A. F. Kuteinikov, Zavodsk. Lab.,36, 160 (1970).

51 K. B. Yatsimirsky, Teoriya Metoda Grafov v Khimii. I7d. 'Naukova Dumka'. Kiev (1971). 


\section{KINETICS OF COMPLEX FORMATION OF METALS}

52 K. Bersh, Teoriya Grafov i ee primenenie, Izd. Inostr. Liter., Moscow (1962).

53 Yu. A. Zolotov, I. P. Alimarin and B. Ya. Spivakov, Izvest. Akad. Nauk SSSR, Ser. Khim., 2, 579 (1969).

54 B. Ya. Spivakov and Yu. A. Zolotov, Zh. Anal. Khim., (Mosk.), 23, 1124 (1968).

${ }_{55}$ H. Bode and K. J. Tusche, Z. Anal. Chem., 157, 414 (1957).

56 J. Stary and K. Kratzer. Anal. Chim. Acta, 40, 93 (1968).

57 B. Ya. Spivakov and Yu. A. Zolotov, Zh. Anal. Khim., (Mosk.), 25, 616 (1970).

58 O. V. Stepanets. Yu. V. Yakovlev and I. P. Alimarin, Zh. Anal. Khim., (Mosk.), 25, 1906 (1970).

59 T. J. Bydalek and D. W. Margerum, Inorg. Chem., 2, 678 (1963).

${ }^{60}$ D. W. Margerum, Z. Physik. Chem., 63, 336 (1959).

61 B. Ya. Spivakov and Yu. A. Zolotov, Zh. Anal. Khim., (Mosk.), 24, 1773 (1969).

${ }^{62}$ G. Eckert, Z. Anal. Chem., 148, 14 (1955).

63 K. P. Stolyarov, Zh. Anal. Khim., (Mosk.), 16, 452 (1961).

${ }^{64}$ K. Motojuma, S. Bando and N. Tamura, Talanta, 14, 1197 (1967).

65 L. I. Budarin, G. A. Rumyantseva and K. B. Yatsimirsky, Zh. Neorgan. Khim., 15, 1775 (1970).

66 D. W. Margerum, I. B. Pausch, G. H. Nyssen and G. F. Smith, Anal. Chem., 41, 233 (1969).

67 I. B. Pausch and D. W. Margerum, Anal. Chem., 41, 226 (1969). 